\title{
Disparities in sexual and reproductive health services utilization among urban and rural adolescents in southern Ethiopia, 2020: a comparative cross-sectional study
}

\author{
Aklilu Habte $^{1^{*}}$, Samuel Dessu², Biruk Bogale ${ }^{3}$ and Lire Lemma ${ }^{1}$
}

\begin{abstract}
Background: Although studies on the uptake of Adolescent sexual and reproductive health (ASRH) services in Ethiopia have been conducted they have failed to show the disparity in service uptake among rural and urban settings. Once the extent and determinants of ASRH service uptake in urban and rural contexts are known, it will be crucial to provide evidence-based information and recommendations for potential interventions to reduce the burden of disease and disability among adolescents. This study aimed at determining the level of SRH service utilization among urban and rural adolescents in the Guraghe zone, Southern Ethiopia.
\end{abstract}

Methods: A community-based comparative cross-sectional study was undertaken from November $1-30,2020$. A multi-stage sampling technique was employed and a total of 1083 adolescents (361 from the urban and 722 from the rural areas) were selected randomly to take part in the study. Pre-tested, interviewer-administered, structured questionnaires were used to collect the data. The data were encoded and entered into Epi-Data version 3.1 and then exported to SPSS version 23 for analysis. $x 2$ test was computed to see a significant difference in SRH service utilization among urban and rural adolescents. In a bivariable logistic regression analysis, a variable with a p-value less than 0.25 has been selected for a multivariable logistic regression model. Variables with $p$-values less than 0.05 were declared statistically significant in multivariate logistic regression.

Results: A total of 1,075 adolescents (358 from urban and 717 from rural) took part in the study, yielding a response rate of 99.3\%. The overall SRH service utilization among the whole adolescents was 39.5\% (95\%Cl: 36.5, 42.4). There was a significant difference in SRH service utilization between urban $56.9 \%(95 \% \mathrm{Cl}: 51.8,62.1)$ and rural 30.8\% (95\%Cl: $27.4,34.2)$ adolescents $(x 2=68.3, p<0.001)$. Residence[AOR $=2.62 ; 95 \% \mathrm{Cl}: 1.63,3.41]$, availability of youth clubs $[\mathrm{AOR}=4.73 ; 95 \% \mathrm{Cl}: 3.43,6.53]$, taking part in peer education $[\mathrm{AOR}=2.06 ; 95 \% \mathrm{Cl}: 1.48,3.88]$, having parental discussion $[\mathrm{AOR}=3.29 ; 95 \% \mathrm{Cl}: 1.73,3.33]$, and being knowledgeable on $\mathrm{SRH}$ issues [AOR $=2.01 ; 95 \% \mathrm{Cl}: 1.45,3.03]$ were identified as a significant determinants of SRH service uptake. Having parental discussion, geographical accessibility, and knowledge on SRH were significant predictors of SRH service uptake among rural adolescents.

Conclusion: Overall, ASRH service utilization in the study area was low, despite urban adolescent service uptake becoming higher than rural adolescents. Since the majority of adolescents were enrolled in schools, schools should

\footnotetext{
*Correspondence: akliluhabte57@gmail.com

'School of Public Health, College of Medicine and Health Sciences,

Wachemo University, Hosanna, Ethiopia

Full list of author information is available at the end of the article
}

(C) The Author(s) 2022. Open Access This article is licensed under a Creative Commons Attribution 4.0 International License, which permits use, sharing, adaptation, distribution and reproduction in any medium or format, as long as you give appropriate credit to the original author(s) and the source, provide a link to the Creative Commons licence, and indicate if changes were made. The images or other third party material in this article are included in the article's Creative Commons licence, unless indicated otherwise in a credit line to the material. If material is not included in the article's Creative Commons licence and your intended use is not permitted by statutory regulation or exceeds the permitted use, you will need to obtain permission directly from the copyright holder. To view a copy of this licence, visit http://creativecommons.org/licenses/by/4.0/. The Creative Commons Public Domain Dedication waiver (http://creativeco mmons.org/publicdomain/zero/1.0/) applies to the data made available in this article, unless otherwise stated in a credit line to the data. 
be an area of intervention to improve adolescents' knowledge of SRH services through mass media, community networks, and interpersonal/group communication. Furthermore, promoting parent-adolescent discussions, as well as peer-to-peer discussions at the family and school level, should be emphasized. Stakeholders in the education and health sectors need to strengthen their efforts to establish youth clubs in places where they do not yet exist, especially in rural schools.

\section{Background}

Adolescence is a crucial period of human development, characterized by rapid physical, psychosocial, intellectual, and emotional maturation, as well as erotic and reproductive maturation $[1,2]$. Healthy adolescents contribute to economic development by rising productivity and preventing the spread of disease through generations. Every dollar spent on adolescent health returns tenfold in terms of health, social, and economic benefits [3].

Adolescent sexual and reproductive health (ASRH) services are described as a set of strategies, procedures, and services aimed at preventing and treating sexual health problems in adolescents while also promoting their overall well-being $[4,5]$. It encourages adolescents' physical and emotional well-being by addressing their desire to avoid unintended pregnancy, unsafe abortion, sexually transmitted infections (STIs) (including HIV/AIDS), and other forms of sexual harassment and pressure $[6,7]$. The constellation of the ASRH services are; provision of information and education on SRH issues, counseling, and provision of modern contraception, volunteered HIV/ AIDS counseling, and testing(VCT), STI diagnosis and management, and safe and/or post-abortion care [6-8].

Adolescents number up to 1.2 billion worldwide, with 513 million between the ages of 15 and 19, and 85 percent of them live in developing countries [9]. They account for up to a quarter of the population in some countries, and their numbers are expected to rise by 2050, especially in low- and middle-income countries (LMICs), where access to health and social services, employment, and livelihoods appears to be under strain [10-12]. In subSaharan Africa, adolescents make up 23\% of the population of the region [11]. Around 25\% of Ethiopia's total population is covered by a cohort of adolescents $[6,13]$.

While the Convention on the Rights of the Child (CRC) protects adolescents' right to SHR services, neither the providers of these services nor the systems under which they operate are equipped to recognize adolescents' needs and benefits [14-16]. In developing countries such as Ethiopia, health systems and programs are primarily designed for young children or adults, with SRH services for adolescents, particularly those living in rural areas, having received less attention [15]. Although underfive mortality decreased by half during the duration of the Millennium Development Goals [17], advances in adolescent mortality have been delayed [16]. There are over 1.2 million adolescent deaths worldwide every year $[10,16]$.

Neglecting adolescent SRH services has serious consequences; adolescent girls, in particular, are at higher risk of unintended pregnancy, HIV and sexually transmitted infections (STIs), sexual coercion, exploitation, and violence $[12,18]$. Every year, nearly 16 million adolescent girls give birth, with the majority of these births occurring in the context of early marriage, and $90 \%$ of these births occurring in developing countries [19]. 7.4 million teen girls have become pregnant unintentionally, due to a shortage of contraceptive options [20]. Up to $68 \%$ of adolescents in sub-Saharan Africa have an unmet need for contraception [20]. In Ethiopia, a third of girls aged 15 to 19 have started having children, with rural settings dominant [21].

According to the 2019 Mini Ethiopian Demographic and Health Survey (mini-EDHS 2019), contraceptive usage among currently married women aged 15-19 years was just $36.5 \%$, with injectable, implants, and IUD use of $27.5 \%, 5.9 \%$, and $0.0 \%$, correspondingly [22]. With $75 \%$ and $80 \%$ respectively, the proportion of adolescents who have never been tested for HIV is highest among women and men aged 15-19 [21]. Limited studies conducted elsewhere in Ethiopia have shown that inadequate access to SRH services in general with a range of $21.5-41.2 \%$ [23-25].

The Federal Ministry of Health (FMOH) of Ethiopia has introduced various strategies to facilitate nationallevel adolescent and youth reproductive health services to overcome SRH problems $[6,13]$. Despite these efforts, Ethiopian adolescents and young adults continue to face significant challenges to reproductive health services [6]. Adolescents in rural and urban areas have different sociodemographic, socioeconomic, and cultural characteristics, which influence how they are using SRH services.

Although studies on the uptake of ASRH services in Ethiopia have been conducted [23-25], they have failed to show the disparity in service uptake among rural and urban settings. Once the extent and determinants of ASRH service uptake in urban and rural contexts are known, it will be crucial to provide evidence-based information and recommendations for potential interventions to reduce the burden of disease and disability among 
adolescents. Furthermore, identifying and recognizing the pattern of SRH service utilization among adolescents can aid in future planning for better service delivery. Hence, this study aimed at assessing the level and determinants of ASRH service utilization among adolescents living in urban and rural districts of the Guraghe zone, southern Ethiopia.

\section{Methods}

\section{Study setting, period, and design}

From November 1 to 30, 2020, a community-based comparative cross-sectional study has been undertaken in the Guraghe Zone, Southern Ethiopia. The zone is $158 \mathrm{~km}$ from Ethiopia's capital, Addis Ababa, and $337 \mathrm{~km}$ from Hawassa (the capital city of southern nation nationalities and people region). For the fiscal year 2020, the Zone's total population was $1,807,689$, with $1,468,940$ (81.3\%) and 338,749 (18.7\%) living in rural and urban districts, respectively. Adolescents between the ages of 15 and 19 constituted $13.6 \%(245,845)$ of the total population. The zone is divided into nine rural districts and four urban administrative, comprised of 174 rural and 27 urban kebeles (the smallest administrative unit next to a district in the Ethiopian government). There are 128 health facilities which are quantified as 74 health centers, 5 hospitals, 168 health posts, 30 private clinics.

\section{The population of the study}

The source populations were all adolescents of age $15-19$ years living in the urban and rural districts of Guraghe zone, whereas the study population consisted of all selected adolescents living in the selected districts during the study period. Adolescents who have lived in the study area for less than six months and those who were seriously ill at the time of data collection were excluded from the study.

\section{Sample size determination}

The sample size was determined by applying a double population proportion formula via StatCalc menu of Epi Info version7.1; considering the proportion of SRH service uptake in Urban $=33.8 \%$ [24] and proportion of SRH service uptake in rural $=21.5 \%$ [23], a $5 \%$ margin of error, power of $80 \%, 1: 2$ urban to rural ratio. Based on the above assumptions, the sample size was 492 (164 from urban and 328 from rural), and after allowing for a $10 \%$ nonresponse rate, and design effect of 2 , the final sample size for this study was 1083(361 from urban and 722 rural).

\section{Sampling procedure}

A multi-stage sampling technique was used to access study participants. Initially, the zone was divided into rural districts and urban administrative. In the first stage, the lottery method was used to select four of the ten rural districts and two of the four town administrative (urban). The two selected town administrative (Urban) were Wolkite town (with 8kebeles) and Butajira town (with 9 kebeles). At stage two 20 rural kebeles, were randomly selected from a total of 59 kebeles in the four rural districts mentioned above. Of the 17 urban kebeles, 7 were selected by lottery method. Finally, the sample size was proportionally allocated to each selected kebele (Fig. 1). With the assistance of community health workers (CHWs), households with eligible participants were coded and a sampling frame was set up. It was practical to access each study participant by simple random sampling (i.e. computer-generated random number). When there was more than one deserving adolescent in the selected household, a lottery method was used.

\section{Data collection tools, methods, and personnel}

After reviewing previously conducted related studies in the areas of interest, pre-tested structured questionnaires have been developed [13, 15, 23-25]. The questionnaire had several sections, including socioeconomic and demographic characteristics, access to SRH services, knowledge of SRH-related issues, respondents' lifestyle and sexual activity, and utilization of RH services. The data was collected by14 diploma nurses with prior data collection expertise under the supervision of six public health officers via a face-to-face interview. All data collectors and supervisors got a one-day intensive training on the study's purpose, methodologies, and data collection techniques. The interviewers returned to the families at least three times at different time intervals when the eligible study participants were not present during data collection. After three visits, if the interviewer was still unable to contact the study participants, he or she went on to the next allocated household.

\section{Data quality management}

The questionnaire was written in English first, then translated into the local language by fluent speakers, and then retranslated back into English by another translator to assure consistency. One week before the actual data collection, a pre-test was conducted on 54 adolescents (5 percent of the sample total) in one of the unselected districts. Based on the results of the pre-test, all necessary changes were made to improve the completion of the questionnaires. Confusing and long questions were removed and shortened as a result of the pre-test.The principal investigator and field supervisors closely oversaw and coordinated the total data collection process. Before analysis, all of the data were double-checked for 


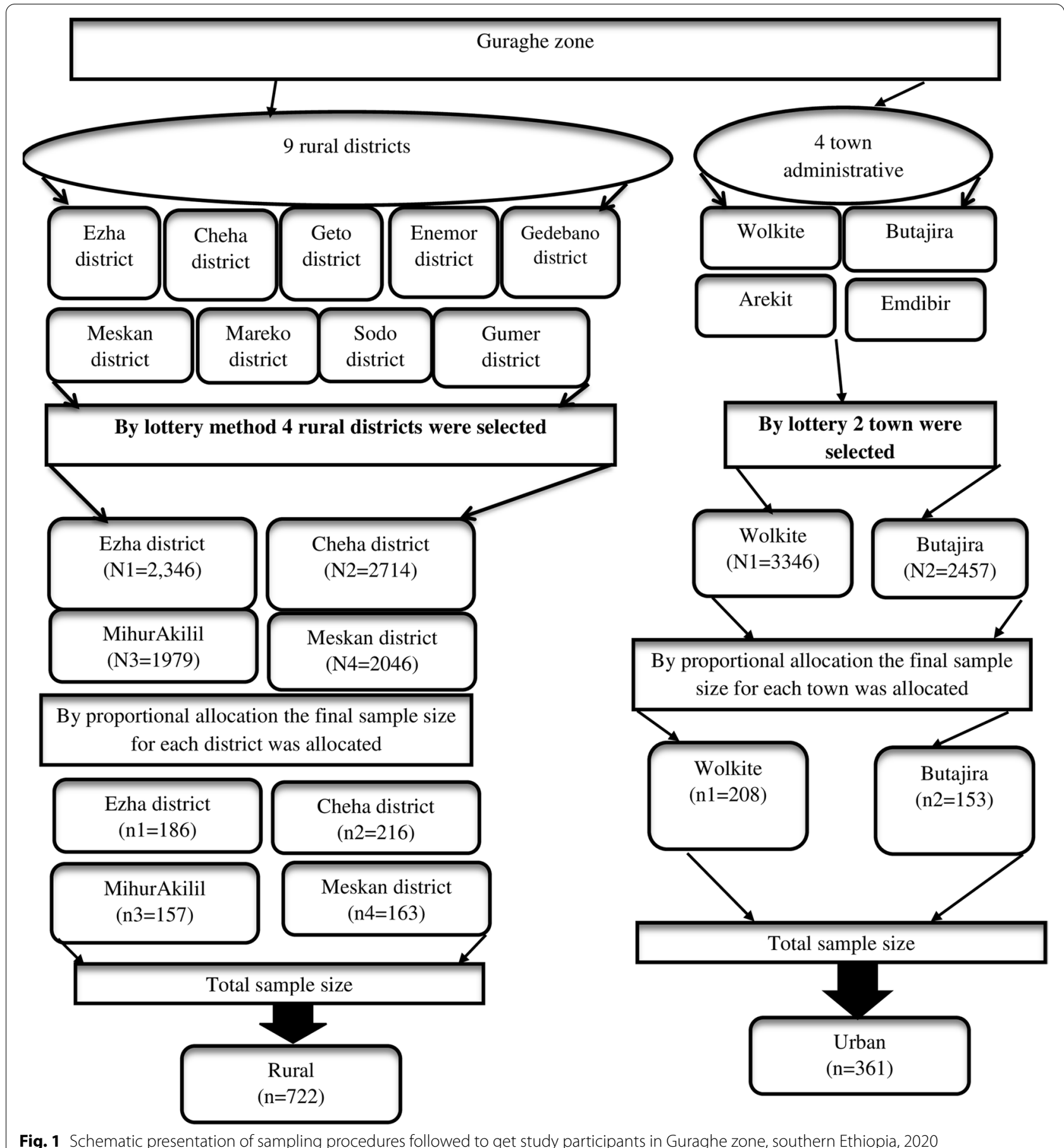

Fig. 1 Schematic presentation of sampling procedures followed to get study participants in Guraghe zone, southern Ethiopia, 2020

completeness and consistency. The data were taken in a quiet area of the study participant's home where there was no noise or disturbance.

\section{Definition and operationalization of study variables}

Sexual and reproductive health (SRH) service utilization: when adolescents received at least one of the five important elements of SRH services; information and education on SRH matters, consultation and provision of modern contraceptives; STIs diagnosis and management, getting VCT service, and abortion and/or postabortion care within the last 12 months [24, 25].

Adolescent: In this study, adolescents denote boys and girls between the ages of 15-19 [24, 26, 27]. 
Parental Discussion on SRH issues: Adolescents who have discussed at least two SRH topics in the previous 12 months(Condom use, STI/HIV/AIDS, abstinence, unwanted pregnancy, contraception) together with their parent/s [24].

Sexual exposure history: Adolescents who had sex in their lives have been identified as having a sexual encounter history and not otherwise [24]

Modern contraceptive service utilization: Adolescents that during the past 12 months have used any of the modern methods of birth control (oral contraceptives, condoms (male and female), injectables, implants, intrauterine devices, emergency contraceptive pills, and spermicidal agents) [24, 26].

Accessibility to SRH service: Applied to the perceived distance traveled by respondents to reach SRH service delivery points and/or time spent by them. Adolescents residing within a $1.6-\mathrm{km}$ radius of the nearest SRH service center and/or reaching those service delivery points within a walking distance of fewer than 30 min were graded as having good and otherwise poor geographical mobility[24].

Substance use: Using addictive substances such as alcohol, 'khat', or cigarettes with either frequency of; more repeated than daily, daily, weekly or monthly in the past 12 months before the study [24].

Reproductive health service knowledge: Twelve questions were asked to adolescents encompassing the perceptions about SRH issues. An index that summarizes the level of knowledge and categorizes it as Knowledgeable if the summary index is equal to or greater than the mean $[23,24]$.

Availability of Youth clubs: Accessibility of places/rooms where young people can meet and gather SRH information, SRH services such as contraceptives, physical activities, social support, peer-to-peer discussion, with the aid of trained workers and volunteers to protect adolescents from negative events, anti-social behavior, crime, drug, and alcohol abuse that are a problem in this community [28-30].

\section{Data analysis}

The data entry was done using EPI Data 3.1 and exported for analysis to SPSS version 23. Using descriptive statistical analysis, frequency, percentage, and mean for explanatory and response variables were run. Chi-square testing was done to see if there was any significant on SRH service uptake among urban and rural adolescents and a statistically significant difference was observed between the two groups $(x 2=68.3, p<0.001)$, indicating that the factors associated with SRH utilization could be different among rural and urban groups. Therefore, the analysis was conducted separately. Bivariable logistic regression was used to find out the relationship between SRH service utilization and the independent variables, and variables with a p-value of less than 0.25 were selected candidates for a multivariable logistic regression(MLR) model. Variables with a p-value less than 0.05 were considered statistically significant in multivariable logistic regression analysis. The AOR and its 95\%CI were used to report the association between SRH service utilization and explanatory variables. The model fitness was assessed using the Hosmer and Lemeshow goodness of fit tests, which yielded a score of 0.59. The variance inflation factors (VIF $>10$ ) were used to check for multicollinearity amongst the explanatory variables.

\section{Results}

Socio-demographic characteristics of respondents

A total of 1,075 adolescents (358 from urban and 717 from rural) took part in the study, yielding a response rate of $99.3 \%$. The mean $( \pm S D)$ age of the adolescents was $17.0 \pm 1.4$ years. Females make up a majority of respondents (622, or $57.9 \%$ ), with $57.3 \%$ and $59.7 \%$ living in urban and rural areas, respectively. Over half of all respondents, 560(52.1\%), attended high school, with 196 (54.7\%) in an urban and $364(50.8 \%)$ in a rural setting. The majority of adolescents in both groups belong to the Guraghe ethnic group (91.6\% in the urban and $91.4 \%$ in the rural) and followers of orthodox religion (urban:56.4.0\% and rural:53.8\%) (Table 1).

\section{Geographical accessibility to ASRH service delivery points} In terms of geographic accessibility, 264 (73.7\%) of urban adolescents and 183 (25.5\%) of rural adolescents were able to access SRH service delivery points within a 30 -min walk of their home $(x 2=228.18, p<0.001)$. Health centers and private clinics were among the service delivery points frequently accessed by 219 (61.2\%) and 174 (48.5\%) of urban adolescents, respectively (Fig. 2). A significant difference in the availability of youth clubs in urban and rural settings in which more than half, 192(53.6\%) of rural and 268(37.4\%) urban adolescents reported that availability of youth clubs (YCs) in their nearby environment $\left(X^{2}=25.767, p<0.001\right)$.

\section{Adolescents' attributes related to sexual and reproductive health}

A total of 227 (21.1\%) adolescents reported having had a sexual partner/s in their lifetime, with 115 (urban: 57 (62.6\%) and rural: 58 (42.6\%) having had sexual intercourse at least once. Between urban and rural adolescents, there was a significant difference in having a parental discussion in the previous 12 months(urban $=165(46.1 \%)$; Rural $=208(29.1 \%), \quad x 2=30.741, \quad P<0.001)$. Unwanted pregnancy was the most common topic addressed during a parental discussion among both urban and rural adolescents, with $134(81.2 \%)$ and 141 (70.1\%), respectively 
Table 1 Socio-demographic characteristics of rural and urban adolescents in Guraghe zone, Southern Ethiopia, 2020

\begin{tabular}{|c|c|c|c|c|}
\hline Variable categories & $\begin{array}{l}\text { Urban }(n=358) \\
n(\%)\end{array}$ & $\begin{array}{l}\text { Rural }(n=717) \\
\mathrm{n}(\%)\end{array}$ & $\begin{array}{l}\text { Total = } 1075 \\
\mathrm{n}(\%)\end{array}$ & Test statistics \\
\hline \multicolumn{5}{|l|}{ Age $(n=1075)$} \\
\hline $15-16$ & $152(42.4)$ & 299(41.7) & $451(41.9)$ & \multirow{3}{*}{$\begin{array}{l}X 2=0.056 \\
P=0.432\end{array}$} \\
\hline $17-19$ & $206(57.6)$ & $418(58.3)$ & $624(58.1)$ & \\
\hline Mean $( \pm$ SD) age $(n=1075)$ & $16.9 \pm 1.4$ & $17.0 \pm 1.4$ & & \\
\hline \multicolumn{5}{|l|}{$\operatorname{Sex}(n=1075)$} \\
\hline Male & $153(42.7)$ & $289(40.3)$ & $442(41.1)$ & \\
\hline Female & 205(57.3) & $428(59.7)$ & 633(58.9) & \\
\hline \multicolumn{5}{|l|}{ Marital status $(n=1075)$} \\
\hline Ever Married & $22(6.1)$ & $34(4.7)$ & $56(5.2)$ & \multirow{2}{*}{$\begin{array}{l}X 2=0.952 \\
P=0.202\end{array}$} \\
\hline Unmarried & 336(93.9) & 683(95.3) & 1019(94.8) & \\
\hline \multicolumn{5}{|l|}{ Educational status $(n=1075)$} \\
\hline No formal education & $12(3.4)$ & $30(4.2)$ & $42(3.9)$ & \multirow{3}{*}{$\begin{array}{l}x 2=1.688 \\
P=0.430\end{array}$} \\
\hline Primary & 150(41.9) & $323(45.0)$ & $473(44.0)$ & \\
\hline Secondary & $196(54.7)$ & $364(50.8)$ & $560(52.1)$ & \\
\hline \multicolumn{5}{|l|}{ Occupational status ( $n=1075$ ) } \\
\hline Student & 283(79.1) & $590(82.3)$ & $873(81.2)$ & \multirow{3}{*}{$\begin{array}{l}x 2=2.030 \\
P=0.362\end{array}$} \\
\hline Daily laborer & $41(11.4)$ & $75(10.4)$ & $116(10.8)$ & \\
\hline Unemployed & $34(9.5)$ & $52(7.3)$ & $86(8.0)$ & \\
\hline \multicolumn{5}{|c|}{ Current living arrangement $(n=1075)$} \\
\hline With bother parent & $301(84.1)$ & $598(83.4)$ & 899(83.6) & \multirow{4}{*}{$\begin{array}{l}X 2=5.62 \\
P=0.132\end{array}$} \\
\hline With mother only & $23(6.4)$ & $61(8.5)$ & $84(7.8)$ & \\
\hline With father only & 20(5.6) & $24(3.4)$ & $44(4.1)$ & \\
\hline With husband or wife & 14(3.9) & $34(4.7)$ & $48(4.5)$ & \\
\hline \multicolumn{5}{|c|}{ Mother's education level $(n=1032)$} \\
\hline No Formal education & 153(45.1) & $398(57.4)$ & $551(53.4)$ & \multirow{4}{*}{$\begin{array}{l}X 2=26.904 \\
P<0.001\end{array}$} \\
\hline Primary & 123(36.3) & 198(28.6) & $321(31.1)$ & \\
\hline Secondary & 29(8.6) & $71(10.2)$ & 100(9.7) & \\
\hline Diploma and above & $34(10.0)$ & $26(3.8)$ & $60(5.8)$ & \\
\hline \multicolumn{5}{|c|}{ Father's educational level $(n=988)$} \\
\hline No formal education & $86(25.9)$ & 252(38.4) & $338(34.2)$ & \multirow{4}{*}{$\begin{array}{l}X 2=62.872 \\
P<0.001\end{array}$} \\
\hline Primary & $83(25.0)$ & $243(37.0)$ & $326(33.0)$ & \\
\hline Secondary & 109(32.8) & $120(18.3)$ & $229(27.2)$ & \\
\hline Diploma and above & $54(16.3)$ & $41(6.3)$ & $95(9.6)$ & \\
\hline \multicolumn{5}{|l|}{ Family size $(n=1075)$} \\
\hline$\leq 5$ & $223(62.3)$ & $349(48.7)$ & $572(53.2)$ & \multirow{2}{*}{$\begin{array}{l}x 2=18.876 \\
P<0.001\end{array}$} \\
\hline$>5$ & $135(37.7)$ & $368(51.3)$ & $503(46.8)$ & \\
\hline
\end{tabular}

(Fig. 3). In terms of substance use, 91 (25.4\%), 106 (29.5\%), and $46(12.8 \%)$ of urban adolescents drunk alcohol chew 'Khat', and smoke cigarettes, respectively (Table 2).

\section{Knowledge of adolescents about SRH related issues}

The level of knowledge of adolescents on SRH issues was assessed using eleven items. As a result, study participants had a mean $( \pm S D)$ knowledge score of $5.4 \pm 2.4$ (5.7 \pm 2.7 in urban and $5.2 \pm 2.3$ in rural).
Nearly half of the study participants, 508 (47.2\%), had a good knowledge of SRH issues, with 186 (51.9\%) in the urban and $322(44.9 \%)$ in the rural. Nearly seven out of ten $(69.3 \%)$ of urban and more than half $(56.8 \%)$ of rural adolescents had information about SRH services and the school environment was found to be the most popular source of information among both urban and rural. At least one form of SRH service that should be provided to an adolescent is reported by 221 (61.7\%) of urban and $343(47.3 \%)$ of rural adolescents (Table 3 ). 


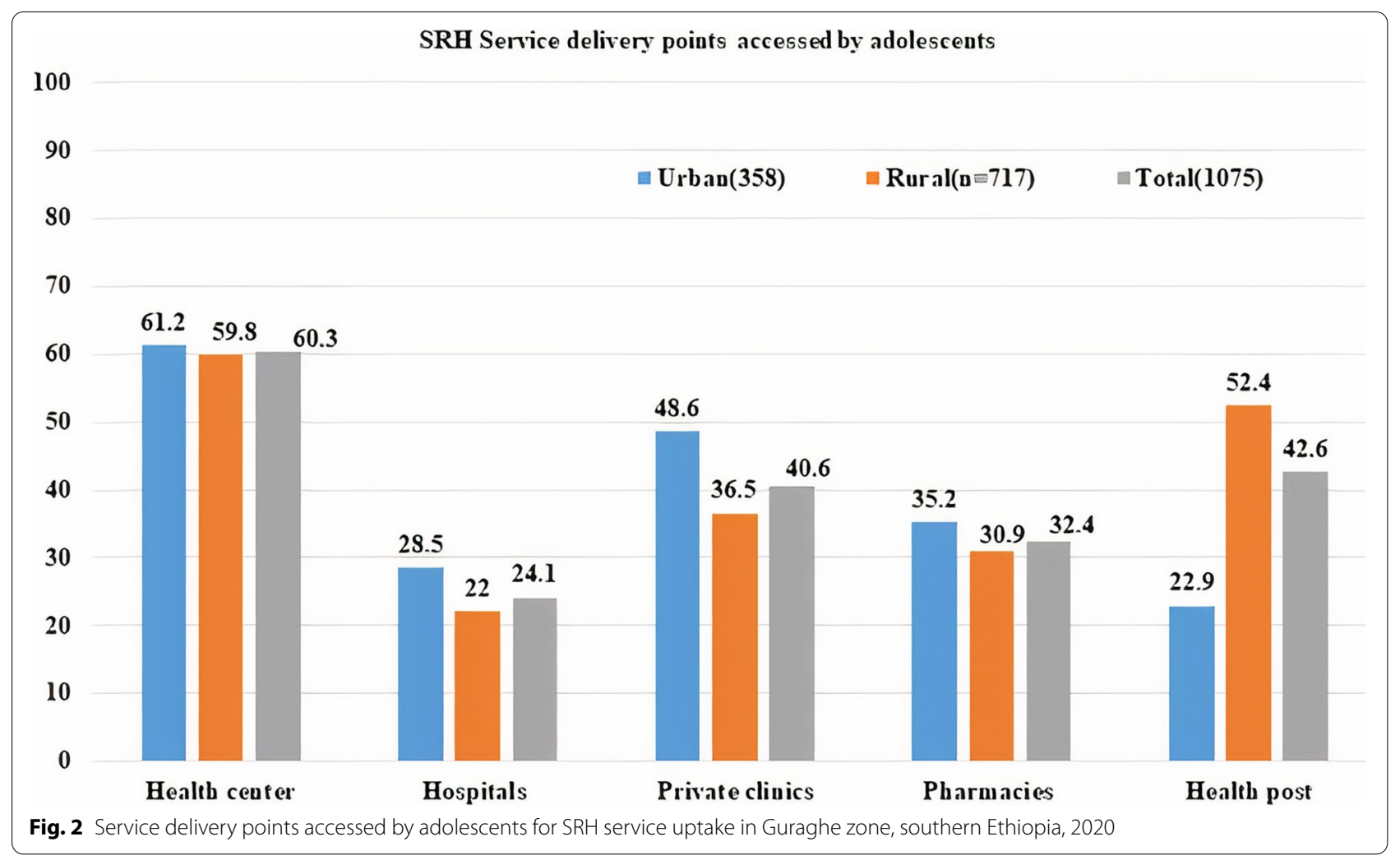

\section{Uptake of SRH services among adolescents}

The overall utilization of SRH service by adolescents was $39.5 \%$ (95\%CI: 36.5, 42.4). There was a significant difference in the rate of SRH service utilization between urban 204(56.9\%) (95\%CI: 51.8, 62.1) and rural 221(30.8\%)
(95\%CI: 27.4, 34.2) adolescents $(\mathrm{X} 2=68.3, p<0.001)$. $\mathrm{SRH}$ information and education was the most frequent SRH service item received by both urban and rural adolescents, with $156(43.6 \%)$ and 217 (30.3\%) respectively. Only $13.7 \%$ of urban and $8.5 \%$ of rural respondents

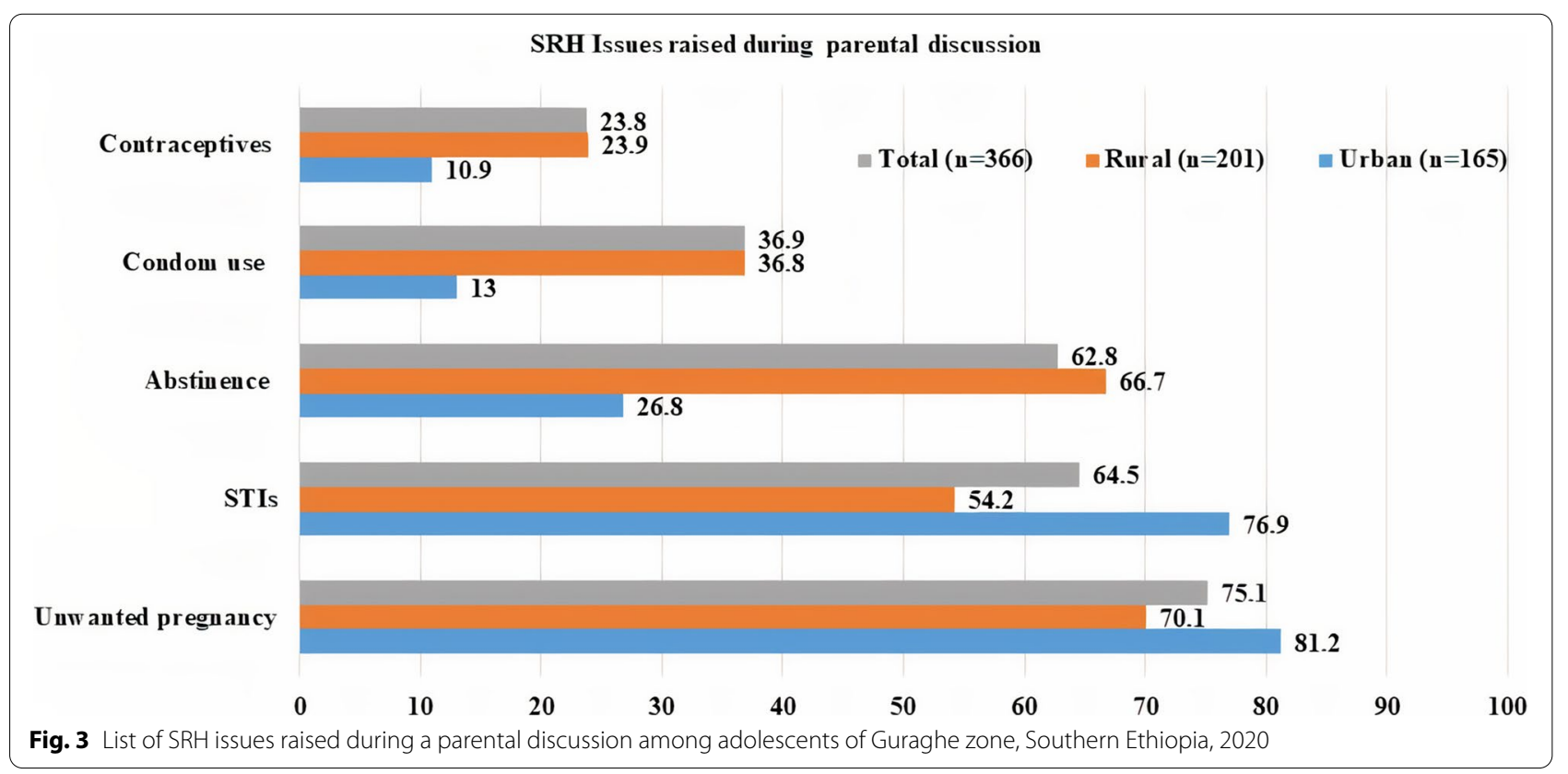


Table 2 Individual attributes related to sexuality and reproductive health among rural adolescents of Guraghe zone, southern Ethiopia, 2020

\begin{tabular}{|c|c|c|c|c|}
\hline Variable categories & $\begin{array}{l}\text { Urban = } 358 \\
\mathrm{n}(\%)\end{array}$ & $\begin{array}{l}\text { Rural }=717 \\
n(\%)\end{array}$ & $\begin{array}{l}\text { Total }=1075 \\
\mathrm{n}(\%)\end{array}$ & Test statistics \\
\hline \multicolumn{5}{|c|}{ Ever Had sexual partner/s $(n=1075)$} \\
\hline Yes & $91(25.4)$ & 136(18.9) & $227(21.1)$ & \multirow{2}{*}{$\begin{array}{l}X 2=5.966 \\
P=0.015\end{array}$} \\
\hline No & 267(74.6) & $581(81.1)$ & $848(78.9)$ & \\
\hline \multicolumn{5}{|c|}{ Number of sexual partners $(n=227)$} \\
\hline One & $55(60.4)$ & 109(80.1) & 164(72.2) & \multirow{3}{*}{$\begin{array}{l}X 2=2.887 \\
P=0.1342\end{array}$} \\
\hline Two & $27(29.7)$ & $25(18.4)$ & $52(22.9)$ & \\
\hline More than two & $9(9.9)$ & $2(1.5)$ & $11(4.9)$ & \\
\hline \multicolumn{5}{|c|}{ Ever had sexual intercourse $(n=227)$} \\
\hline Yes & $57(62.6)$ & $58(42.6)$ & 115(50.7) & \multirow{2}{*}{$\begin{array}{l}X 2=6.755 \\
P=0.011\end{array}$} \\
\hline No & $34(37.4)$ & $78(57.4)$ & $112(49.3)$ & \\
\hline \multicolumn{5}{|c|}{ Ever consumed Alcohol $(n=1075)$} \\
\hline Yes & $91(25.4)$ & $151(21.1)$ & $242(22.5)$ & \multirow{2}{*}{$\begin{array}{l}X 2=2.601 \\
P=0.063\end{array}$} \\
\hline No & 267(74.6) & $566(78.9)$ & $833(77.5)$ & \\
\hline \multicolumn{5}{|c|}{ Frequency of alcohol consumption ( $n=242)$} \\
\hline Almost every day & $4(4.4)$ & $11(7.3)$ & $15(6.2)$ & \\
\hline At least once a week & $8(8.8)$ & $14(9.3)$ & $22(9.1)$ & \\
\hline At least once a month & 13(14.3) & 16(10.6) & $29(12.0)$ & \\
\hline At least once a year & $56(61.5)$ & $87(57.6)$ & 143(59.1) & \\
\hline Ceased currently ${ }^{\mathrm{a}}$ & 10(11.0) & 23(15.2) & $33(13.6)$ & \\
\hline \multicolumn{5}{|c|}{ He/she Ever chew ‘Khat' $(n=1075)$} \\
\hline Yes & 106(29.6) & 178(24.8) & $284(26.4)$ & \multirow{2}{*}{$\begin{array}{l}x^{2}=2.810 \\
P=0.055\end{array}$} \\
\hline No & 252(70.4) & $539(75.2)$ & $791(73.6)$ & \\
\hline \multicolumn{5}{|c|}{ Frequency khat chewing $(n=284)$} \\
\hline Almost every day & $6(5.7)$ & $2(1.1)$ & $8(2.8)$ & \\
\hline At least once a week & $37(34.9)$ & $68(38.2)$ & $105(37.0)$ & \\
\hline At least once a month & $41(38.7)$ & $74(41.6)$ & $115(40.5)$ & \\
\hline At least once a year & 10(9.4) & $14(7.9)$ & 24(8.4) & \\
\hline Not current users ${ }^{\mathrm{a}}$ & $12(11.3)$ & $20(11.2)$ & $32(11.3)$ & \\
\hline \multicolumn{5}{|c|}{ She/he ever smoke a cigarette $(n=1075)$} \\
\hline Yes & $46(12.8)$ & $63(8.8)$ & 109(10.1) & \multirow{2}{*}{$\begin{array}{l}x^{2}=4.262 \\
P=0.026\end{array}$} \\
\hline No & $312(87.2)$ & $654(91.2)$ & $966(89.9)$ & \\
\hline \multicolumn{5}{|c|}{ Frequency smoking $(n=109)$} \\
\hline Almost every day & $2(4.3)$ & $3(4.8)$ & $5(4.6)$ & \\
\hline At least once a week & $6(13.0)$ & $4(6.3)$ & $10(9.2)$ & \\
\hline At least once a month & $9(19.6)$ & $8(12.7)$ & 17(15.6) & \\
\hline At least once a year & $9(19.6)$ & $24(38.1)$ & $33(30.3)$ & \\
\hline Ceased currently ${ }^{\mathrm{a}}$ & $20(43.5)$ & $24(38.1)$ & $44(40.4)$ & \\
\hline
\end{tabular}

${ }^{a}$ Adolescents who have taken none of the above substances in the past three months

received STI Diagnosis and Management services (Fig. 4).

\section{Reasons for not using SRH service among adolescents}

Lack of convenient or separate rooms for SRH service delivery was reported by $452(69.5 \%)$ adolescents as the most prevalent hindrance to SRH service uptake (urban: 96 (62.3\%) and rural: 356(71.8\%). Lack of well-trained health care providers(HCPs) on SRH service was the other reason mentioned by $54(35.1 \%)$ of urban adolescents. Far distance to nearby health facilities was another prominent reason mentioned by $319(64.3 \%$ ) of rural adolescents (Fig. 5). 
Table 3 Level of SRH knowledge of adolescents of Guraghe zone, Southern Ethiopia, 2020

\begin{tabular}{|c|c|c|c|c|c|}
\hline \multirow[t]{2}{*}{ Variable categories } & \multirow{2}{*}{$\begin{array}{l}\text { Urban }=358 \\
n(\%)\end{array}$} & \multirow{2}{*}{$\begin{array}{l}\text { Rural } \\
=717 \\
\mathrm{n}(\%)\end{array}$} & \multirow{2}{*}{$\begin{array}{l}\text { Total } \\
=1075 \\
n(\%)\end{array}$} & \multirow[t]{2}{*}{$x^{2}$} & \multirow[t]{2}{*}{ P-value } \\
\hline & & & & & \\
\hline \multicolumn{6}{|c|}{ Ever heard about SRH $(n=1075)$} \\
\hline Yes & $257(71.8)$ & $353(49.2)$ & $610(56.7)$ & \multirow[t]{2}{*}{49.489} & \multirow[t]{2}{*}{$<0.001$} \\
\hline No & $101(28.2)$ & $364(50.8)$ & $465(43.3)$ & & \\
\hline \multicolumn{6}{|c|}{ Source of information $(n=610)$} \\
\hline From school & 256(99.6) & $280(79.3)$ & $536(87.9)$ & 57.443 & $<0.001$ \\
\hline Radio & $186(72.4)$ & $205(58.1)$ & $351(57.5)$ & 13.215 & $<0.001$ \\
\hline Television & $116(45.3)$ & $67(18.9)$ & 183(30.0) & 48.451 & $<0.001$ \\
\hline Family members & $52(20.2)$ & 133(36.7) & 185(30.3) & 22.609 & $<0.001$ \\
\hline Social media & $45(17.5)$ & $55(15.6)$ & $100(16.4)$ & 0.691 & 0.231 \\
\hline \multicolumn{6}{|c|}{ Can mention at least one SRH service that should be delivered to an adolescent $(n=1075)$} \\
\hline Yes & 230(64.2) & $361(50.3)$ & $591(55.0)$ & \multirow[t]{2}{*}{18.631} & \multirow[t]{2}{*}{$<0.001$} \\
\hline No & 128(35.8) & $356(49.7)$ & $484(45.0)$ & & \\
\hline \multicolumn{6}{|c|}{ Know SRH service delivery points $(n=1075)$} \\
\hline Yes & 206(57.6) & $360(50.2)$ & $566(52.7)$ & \multirow[t]{2}{*}{5.150} & \multirow[t]{2}{*}{0.014} \\
\hline No & $152(42.4)$ & $357(49.8)$ & $509(47.3)$ & & \\
\hline \multicolumn{6}{|c|}{ Know SRH service provider $(n=1075)$} \\
\hline Yes & 229(63.9) & $323(45.1)$ & $552(51.3)$ & \multirow[t]{2}{*}{34.206} & \multirow[t]{2}{*}{$<0.001$} \\
\hline No & 129(36.1) & $394(54.9)$ & $523(48.7)$ & & \\
\hline \multicolumn{6}{|c|}{ Know the reasons for unintended pregnancy } \\
\hline Yes & 229(63.9) & $431(60.1)$ & $660(61.4)$ & \multirow[t]{2}{*}{1.497} & \multirow[t]{2}{*}{0.123} \\
\hline No & 129(36.1) & 286(39.9) & 415(38.6) & & \\
\hline \multicolumn{6}{|c|}{ Know at least one way of avoiding pregnancy } \\
\hline Yes & 190(53.1) & $412(57.5)$ & $602(56.0)$ & \multirow[t]{2}{*}{1.867} & 0.097 \\
\hline No & 168(46.9) & $305(42.5)$ & $473(44.0)$ & & \\
\hline Know at least one type & & & & & \\
\hline Yes & $213(59.5)$ & $383(53.4)$ & $596(55.4)$ & 3.573 & 0.034 \\
\hline No & $145(40.5)$ & $334(46.6)$ & $479(44.6)$ & & \\
\hline Know at least one met & prevention & & & & \\
\hline Yes & $201(56.1)$ & $419(58.4)$ & $620(57.7)$ & 0.514 & 0.257 \\
\hline No & 157(43.9) & 298(41.6) & $455(42.3)$ & & \\
\hline Know the place where & are managed & & & & \\
\hline Yes & 137(38.3) & $261(36.4)$ & 398(37.0) & 0.357 & 0.297 \\
\hline No & $221(61.7)$ & $456(63.6)$ & $677(63.0)$ & & \\
\hline Know at least one ben & traceptives & & & & \\
\hline Yes & $248(69.3)$ & $479(66.8)$ & $727(67.6)$ & 0.664 & 0.228 \\
\hline No & $110(30.7)$ & 238(33.2) & $348(32.4)$ & & \\
\hline Know at least one typ & ceptive & & & & \\
\hline Yes & $222(62.0)$ & $431(60.1)$ & $653(60.7)$ & 0.361 & 0.297 \\
\hline No & 136(38.0) & 286(39.9) & $422(39.3)$ & & \\
\hline Overall knowledge & & & & & \\
\hline Knowledgeable & 186(51.9) & $322(44.9)$ & $508(47.2)$ & 4.756 & 0.029 \\
\hline Not knowledgeable & $172(48.1)$ & 395(55.1) & $567(52.8)$ & & \\
\hline
\end{tabular}

\section{Determinants of SRH service utilization}

To identify determinants of SRH service uptake, we fitted three different models. The first model was used to assess the overall factors that determine the use of SRH services. Five variables were identified as significant determinants of SRH service uptake among the entire adolescents in MLR analysis: residence, having a peer-to-peer education, having a parental discussion, availability of YFS units, and being knowledgeable on SRH issues. 

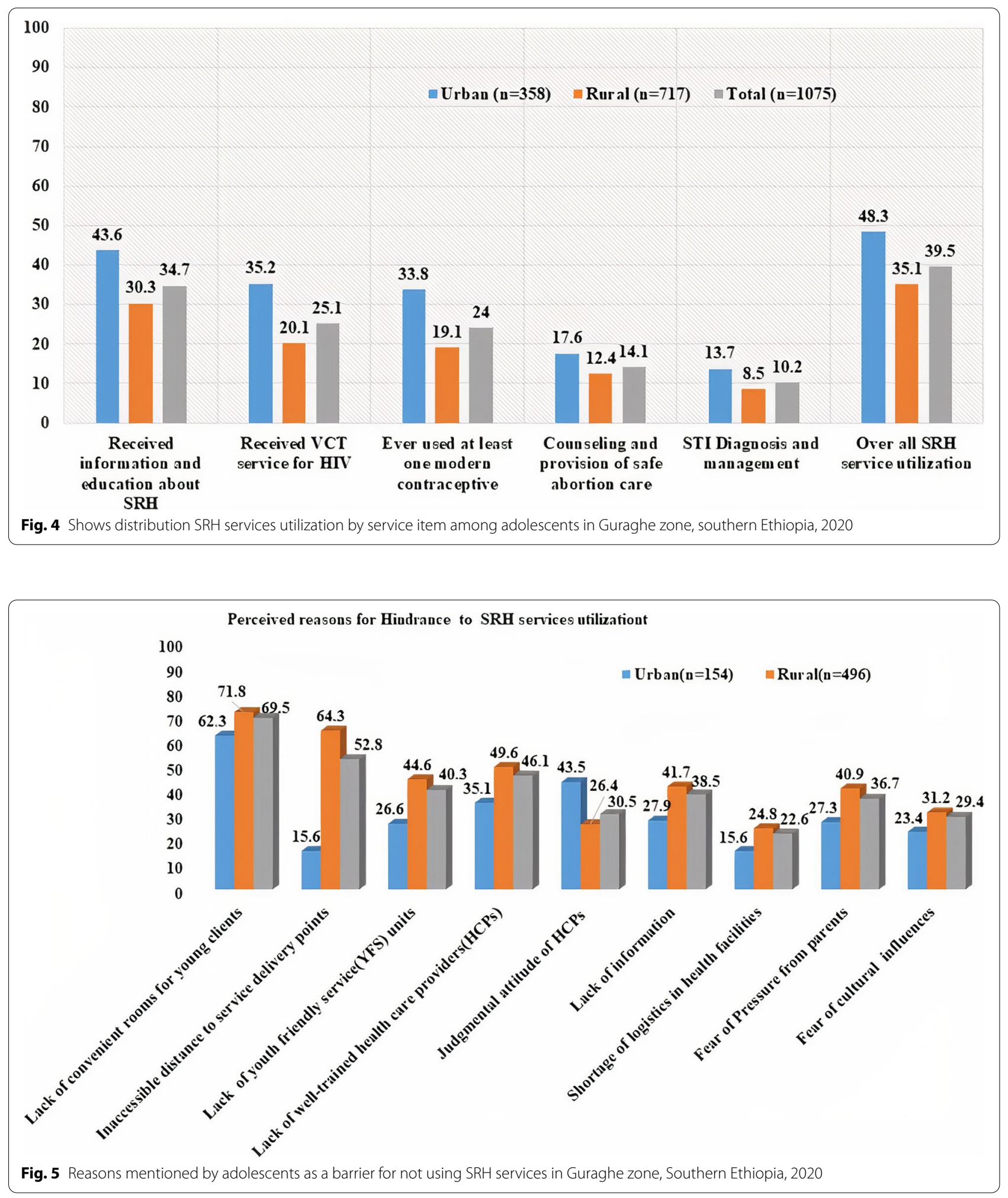
Urban adolescents had a 2.64 times greater chance of accessing SRH services than rural adolescents $[\mathrm{AOR}=2.64 ; 95 \% \mathrm{CI}: 1.63,3.41]$. Adolescents who took part in peer-to-peer education were twice as likely as their counterparts to use $\mathrm{SRH}$ services $[\mathrm{AOR}=2.06 ; 95 \% \mathrm{CI}$ : $1.48,3.88]$. The presence of Youth clubs in their immediate vicinity influences the use of SRH services. Adolescents who lived in areas with functioning youth clubs(YCs) units had a 4.7 times greater chance of using SRH services than their counterparts $[\mathrm{AOR}=4.73 ; 95 \% \mathrm{CI}: 3.43,6.53]$. It was revealed that having a parent discussion about SRH had a positive influence on SRH service adoption. Adolescents who had a parental discussion had a 3.3 times higher chance of using SRH services than those who did not $[\mathrm{AOR}=3.29 ; 95 \% \mathrm{CI}: 2.36,5.59]$. Furthermore, adolescents who were knowledgeable on SRH matters had a 2 times higher likelihood of using SRH services than their counterparts $[\mathrm{AOR}=2.01$; 95\% CI: 1.45 , 3.03] (Table 4).

The second model was fitted only for urban adolescents, and two variables were identified as significant determinants of SRH service uptake: the availability of youth clubs in their local environment and having a parental discussion about SRH issues. Adolescents who lived in areas with functioning youth clubs were 5 times more likely to use SRH services than their counterparts[AOR $=5.06$; 95\%CI: 2.92,8.77]. Adolescents who had a parental discussion about SRH topics within the last 12 months had a more than 3 times greater chance of receiving SRH services than those who did not $[\mathrm{AOR}=3.25$; 95\% CI: 2.01,5.67] (Table 5).

The third model was designed particularly for rural adolescents. As a result, rural adolescents with adequate SRH knowledge were 2.9 times more likely than their counterparts to receive $\mathrm{SRH}$ services $[\mathrm{AOR}=2.93$; 95\%CI: 1.94, 4.43]. Adolescents who lived in areas with functioning youth clubs were 4.2 times more likely to use SRH services than their counterparts[AOR $=4.23$; 95\%CI: 2.83,6.32]. Similarly, adolescents who had a parental discussion about SRH topics were 2 times more likely than those who did not $[\mathrm{AOR}=2.09 ; 95 \% \mathrm{CI}$ : 1.37 , 3.20] to use SRH services. Geographical accessibility to nearby health facilities was also found as a significant predictor of SRH service uptake among rural adolescents. Those adolescents who had to travel less than $30 \mathrm{~min}$ to access a health facility were 2.1 times more likely to utilize SRH services than those who traveled $30 \mathrm{~min}$ and more $[$ AOR $=2.1 ; 95 \%$ CI: 1.36,3.23] (Table 6).

\section{Discussion}

One of the most important health indicators for young people's immediate and long-term SRH needs is the Adolescent Sexual and Reproductive Health (ASRH) program $[7,15]$. This study aimed at comparing SHR service uptake and their determinants among adolescents in urban and rural settings. Overall, 39.5\%( 95\%CI: 36.5, 42.4) of adolescents used SRH services. This finding was comparable with studies conducted in Awabel district, Northwest Ethiopia (41.2\%), and Jimma Zone, southwest Ethiopia(41.1\%) [25, 31]. There was a significant difference in SRH service adoption between adolescents in rural areas (30.8\%) and urban (56.9\%) areas. The current study found that SRH service uptake among urban adolescents was higher than in a similar study conducted in Debre Birhan town, Northern Ethiopia(33.3\%), and Adama town, Eastern Ethiopia (34.0\%) [24, 32]. This disparity may be explained by the time difference between those studies in which adolescent health is being prioritized through enhancing peer-to-peer education at the school level and providing youth clubs in the community.

There was a significant difference between the two groups when it came to individual components of the SRH service. $43.6 \%$ of urban and $30.3 \%$ of rural adolescents received SRH information and education. As compared to studies conducted elsewhere in Ethiopia, these figures were lower $[24,26,27]$. The use of modern contraception was assessed by asking for at least one form of method-mix in the previous 12 months. Only $34.7 \%$ of adolescents (urban $=33.8 \%$ and rural $=30.3 \%$ ) were received at least one type of contraceptive, which was lower than the Mini-EDHS 2019 survey (36.5\%) [22] and studies conducted in the Awabel district(45.4\%) [25], Gondar city (79.5\%) [26], Gobba city (71.4\%) [27], Mekele city (85.8\%) [33] and Anchar district (39.3\%) [34]. The current study in which significant segments of adolescents were unable to obtain the majority of SRH service. Inaccessibility of service delivery points may be a contributing factor in the current study area's low coverage of all SRH services; as a result, a concerted effort and collaboration among local government and non-government stakeholders are needed to make services more available to improve SRH service provision.

Residence, having a peer-to-peer education, having a parental discussion, the availability of a youth club, and being knowledgeable on SRH issues were identified as factors that influence the uptake of SRH services among the whole adolescents.

Urban adolescents had a 2.64 times greater chance of utilizing SRH services than rural adolescents. The possible justification is that urban adolescents may have access to a variety of SRH programs tailored to their age in close surroundings through youth clubs and socio-cultural and economic contexts, which might improve service uptake [18]. In Ethiopia, health care coverage is relatively high in urban than rural [35]. Furthermore, adolescents in urban areas are more likely to receive information about ASRH programs from health care providers and mass media such as radio and television, which may have contributed 
Table 4 Determinants of SRH Service Utilization among urban and rural adolescents in Guraghe Zone, Southern Ethiopia, 2020

\begin{tabular}{|c|c|c|c|c|c|}
\hline \multirow[t]{2}{*}{ Variable categories } & \multicolumn{2}{|c|}{ SRH services utilization } & \multirow[b]{2}{*}{$\operatorname{COR}(95 \% \mathrm{Cl})$} & \multirow[b]{2}{*}{$\mathrm{AOR}(95 \% \mathrm{Cl})$} & \multirow[b]{2}{*}{ p-value } \\
\hline & Yes (\%) & No (\%) & & & \\
\hline \multicolumn{6}{|l|}{ Residence } \\
\hline Rural & $221(52.0)$ & $496(76.3)$ & 1 & 1 & 1 \\
\hline Urban & 204(48.0) & $154(23.7)$ & $2.97(2.29,3.86)^{\mathrm{a}}$ & $2.64(1.63,3.41)^{b}$ & $<0.001$ \\
\hline \multicolumn{6}{|l|}{ Age( in years) } \\
\hline $15-16$ & $171(40.2)$ & $280(43.1)$ & 1 & & \\
\hline $17-19$ & 254(59.8) & $370(56.9)$ & $1.12(0.88,1.44)$ & & \\
\hline \multicolumn{6}{|l|}{ Sex } \\
\hline Female & 234(55.1) & $399(61.4)$ & 1 & 1 & \\
\hline Male & 191(44.9) & $251(38.6)$ & $1.29(1.01,1.66)^{\mathrm{a}}$ & $1.26(0.91,1.75)$ & 0.158 \\
\hline \multicolumn{6}{|c|}{ Current school enrolment } \\
\hline No & $31(7.3)$ & $68(10.5)$ & 1 & & \\
\hline Yes & $394(92.7)$ & $582(89.5)$ & $1.48(0.95,2.31)^{\mathrm{a}}$ & $1.26(0.69,2.30)$ & 0.460 \\
\hline \multicolumn{6}{|l|}{ Educational status } \\
\hline No formal education & $12(2.8)$ & $30(4.6)$ & 1 & 1 & \\
\hline Primary & $155(36.5)$ & $318(48.9)$ & $1.22(0.61,2.44)$ & $0.87(0.34,2.23)$ & 0.769 \\
\hline Secondary & $258(60.7)$ & $302(46.5)$ & $2.14(1.07,4.26)^{\mathrm{a}}$ & $1.29(0.50,3.28)$ & 0.600 \\
\hline \multicolumn{6}{|c|}{ Current living arrangement } \\
\hline With husband/ wife & $13(3.1)$ & $35(5.4)$ & 1 & & \\
\hline With father only & $16(3.8)$ & $28(4.3)$ & $1.54(0.63,3.73)$ & & \\
\hline With mother only & $31(7.3)$ & $53(8.2)$ & $1.57(0.72,3.42)$ & & \\
\hline With bother parent & $365(85.9)$ & $534(82.1)$ & $1.64(0.86,3.53)$ & & \\
\hline \multicolumn{6}{|l|}{ Mother's education level } \\
\hline No Formal education & $215(52.7)$ & $336(53.9)$ & 1 & & 1 \\
\hline Primary & $108(26.4)$ & $213(34.1)$ & $0.79(0.59,1.06)$ & $0.68(0.47,0.98)$ & 0.071 \\
\hline Secondary & $48(11.8)$ & $52(8.3)$ & $1.44(0.94,2.21)^{\mathrm{a}}$ & $1.48(0.87,2.52)$ & 0.152 \\
\hline Diploma and above & $37(9.1)$ & $23(3.7)$ & $2.51(1.45,4.35)^{\mathrm{a}}$ & $1.72(0.86,3.45)$ & 0.127 \\
\hline \multicolumn{6}{|c|}{ Father's educational level } \\
\hline No formal education & $126(32.3)$ & $212(35.5)$ & 1 & & 1 \\
\hline Primary & 112(28.6) & 214(35.8) & $0.88(0.64,1.21)$ & $1.13(0.75,1.68)$ & 0.558 \\
\hline Secondary & $101(25.8)$ & $128(21.5)$ & $1.33(0.94,1.87)^{\mathrm{a}}$ & $1.11(0.72,1.71)$ & 0.622 \\
\hline Diploma and above & $52(13.3)$ & $43(7.2)$ & $2.03(1.28,3.22)^{\mathrm{a}}$ & $1.33(0.73,2.39)$ & 0.350 \\
\hline \multicolumn{6}{|l|}{ Family size } \\
\hline$>5$ & 195(45.9) & $308(47.4)$ & 1 & & \\
\hline$\leq 5$ & $230(54.1)$ & $342(52.6)$ & $1.06(0.83,1.36)$ & & \\
\hline \multicolumn{6}{|c|}{ Geographical accessibility } \\
\hline $\operatorname{Far}(\geq 30 \mathrm{~min})$ & $207(48.7)$ & $421(64.8)$ & 1 & 1 & \\
\hline Close $(<30 \mathrm{~min})$ & $218(51.3)$ & $229(35.2)$ & $1.94(1.51,2.48)^{\mathrm{a}}$ & $1.04(0.73,1.49)$ & 0.813 \\
\hline \multicolumn{6}{|c|}{ Availability of youth clubs } \\
\hline No & 144(33.9) & $471(72.5)$ & 1 & & \\
\hline Yes & $281(66.1)$ & $179(27.5)$ & $5.13(3.94,6.69)^{\mathrm{a}}$ & $4.73(3.43,6.53)^{b}$ & $<0.001$ \\
\hline \multicolumn{6}{|c|}{ Ever had sexual partner/s } \\
\hline No & $326(76.7)$ & $522(80.3)$ & 1 & 1 & \\
\hline Yes & $99(23.3)$ & $128(19.7)$ & $1.24(0.92,1.67)^{\mathrm{a}}$ & $1.44(0.98,2.13)$ & 0.065 \\
\hline \multicolumn{6}{|c|}{ Had a parental discussion on SRH issues } \\
\hline No & $190(44.7)$ & $512(78.8)$ & 1 & 1 & 1 \\
\hline Yes & 235(55.3) & $138(21.2)$ & $4.58(3.54,6.06)^{\mathrm{a}}$ & $3.29(2.36,5.59)^{\mathrm{b}}$ & 0.001 \\
\hline \multicolumn{6}{|c|}{ Participated in peer to peer education } \\
\hline No & $120(28.2)$ & $320(49.2)$ & 1 & & \\
\hline Yes & $305(71.8)$ & $330(50.8)$ & $2.46(1.89,3.20)^{\mathrm{a}}$ & $2.06(1.47,3.88)$ & 0.015 \\
\hline Knowledge of SRH issu & & & & & \\
\hline Not knowledgeable & 165(38.8) & $402(61.9)$ & 1 & 1 & \\
\hline Knowledgeable & $260(61.2)$ & $248(38.1)$ & $2.55(1.99,3.28)^{\mathrm{a}}$ & $2.01(1.45,3.03)$ & 0.001 \\
\hline
\end{tabular}

Key: 1: Reference category; AOR Adjusted odds ratio, COR Crude odds ratio

${ }^{\text {a }}$ statistically significant at $p$-value $<0.25,{ }^{\text {b }}$ statistically significant at $p$-value $<0.05$ 
Table 5 Determinants of SRH Service Utilization among urban adolescents in Guraghe Zone, Southern Ethiopia, 2020

\begin{tabular}{|c|c|c|c|c|c|}
\hline \multirow[t]{2}{*}{ Variable categories } & \multicolumn{2}{|c|}{ SRH services utilization } & \multirow[t]{2}{*}{$\operatorname{COR}(95 \% \mathrm{Cl})$} & \multirow[t]{2}{*}{$\mathrm{AOR}(95 \% \mathrm{Cl})$} & \multirow[t]{2}{*}{ p-value } \\
\hline & Yes (\%) & No (\%) & & & \\
\hline \multicolumn{6}{|l|}{ Age( in years) } \\
\hline $15-16$ & $82(40.2)$ & $70(45.4)$ & 1 & & \\
\hline $17-19$ & $122(59.8)$ & $84(54.6)$ & $1.24(0.81,1.89)$ & & \\
\hline \multicolumn{6}{|l|}{ Sex } \\
\hline Female & $111(54.4)$ & $94(61.0)$ & 1 & 1 & \\
\hline Male & 93(45.6) & $60(39.0)$ & $1.31(0.86,2.01)^{\mathrm{a}}$ & $1.31(0.75,2.29)$ & 0.342 \\
\hline \multicolumn{6}{|c|}{ Current enrolment at school } \\
\hline No & $16(7.8)$ & $21(13.6)$ & 1 & 1 & \\
\hline Yes & 188(92.2) & 133(86.4) & $1.86(0.93,3.68)^{\mathrm{a}}$ & $1.74(0.70,4.28)$ & 0.230 \\
\hline \multicolumn{6}{|l|}{ Educational status } \\
\hline No formal education & $6(2.9)$ & $6(3.9)$ & 1 & 1 & \\
\hline Primary & $66(32.4)$ & $84(54.5)$ & $0.79(0.24,2.55)$ & $0.65(0.15,2.93)$ & 0.578 \\
\hline Secondary & $132(64.7)$ & $64(41.6)$ & $2.06(0.64,6.65)^{\mathrm{a}}$ & $1.30(0.29,5.83)$ & 0.727 \\
\hline \multicolumn{6}{|c|}{ Current living arrangement } \\
\hline With husband/ wife & $8(3.9)$ & $6(3.9)$ & 1 & & \\
\hline With father only & $9(4.4)$ & $11(7.2)$ & $0.61(0.15,2.43)$ & & \\
\hline With mother only & $14(6.9)$ & $9(5.8)$ & $1.17(0.30,4.49)$ & & \\
\hline With bother parent & 173(84.8) & $128(83.1)$ & $1.01(0.34,2.99)$ & & \\
\hline \multicolumn{6}{|l|}{ Mother's education level } \\
\hline No Formal education & $78(40.2)$ & $75(51.7)$ & 1 & 1 & 1 \\
\hline Primary & $72(37.1)$ & $51(35.2)$ & $1.36(0.84,2.19)^{\mathrm{a}}$ & $1.37(0.49,3.76)$ & 0.541 \\
\hline Secondary & $20(10.3)$ & $9(6.2)$ & $2.14(0.91,4.99)^{\mathrm{a}}$ & $1.82(0.64,5.18)$ & 0.258 \\
\hline Diploma and above & $24(12.4)$ & $10(6.9)$ & $2.31(1.03,5.15)^{\mathrm{a}}$ & $1.63(0.87,3.03)$ & 0.126 \\
\hline \multicolumn{6}{|c|}{ Father's educational level } \\
\hline No formal education & $46(24.6)$ & $40(27.6)$ & 1 & 1 & 1 \\
\hline Primary & $38(20.3)$ & $45(31.0)$ & $0.73(0.40,1.34)$ & $1.07(0.49,2.34)$ & 0.866 \\
\hline Secondary & $64(34.2)$ & $45(31.0)$ & $1.24(0.69,2.19)$ & $1.23(0.62,2.45)$ & 0.556 \\
\hline Diploma and above & $39(20.9)$ & $15(10.4)$ & $2.26(1.09,4.69)^{\mathrm{a}}$ & $2.09(0.84,5.18)$ & 0.112 \\
\hline \multicolumn{6}{|l|}{ Family size } \\
\hline$>5$ & $70(34.3)$ & $65(42.2)$ & 1 & 1 & 1 \\
\hline$\leq 5$ & 134(65.6) & $89(57.8)$ & $1.39(0.91,2.15)^{\mathrm{a}}$ & $1.41(0.81,2.44)$ & 0.226 \\
\hline \multicolumn{6}{|c|}{ Geographical accessibility } \\
\hline $\operatorname{Far}(\geq 30 \mathrm{~min})$ & $46(22.5)$ & $48(31.2)$ & 1 & 1 & 1 \\
\hline Close (<30 min) & $158(77.5)$ & $106(68.8)$ & $1.56(0.97,2.49)^{\mathrm{a}}$ & $1.42(0.78,2.58)$ & 0.249 \\
\hline \multicolumn{6}{|c|}{ Availability of Youth clubs } \\
\hline No & $59(28.9)$ & 107(69.5) & & 1 & \\
\hline Yes & $145(71.1)$ & $47(30.5)$ & $5.59(3.54,8.84)^{\mathrm{a}}$ & $5.06(2.92,8.77)^{b}$ & $<0.001$ \\
\hline \multicolumn{6}{|c|}{ Ever had sexual partner/s } \\
\hline No & 143(70.1) & 124(80.5) & 1 & 1 & \\
\hline Yes & $61(29.9)$ & $30(19.5)$ & $1.76(1.07,2.90)^{\mathrm{a}}$ & $1.72(0.90,3.30)$ & 0.101 \\
\hline \multicolumn{6}{|c|}{ Had a parental discussion on SRH issues } \\
\hline No & $81(39.7)$ & $112(72.7)$ & 1 & & \\
\hline Yes & 123(60.3) & $42(27.3)$ & $4.05(2.58,6.36)^{\mathrm{a}}$ & $3.25(2.01,5.67)^{\mathrm{b}}$ & $<0.001$ \\
\hline \multicolumn{6}{|c|}{ Participated in peer to peer education } \\
\hline No & $61(29.9)$ & $64(41.6)$ & 1 & & \\
\hline Yes & 143(70.1) & $90(58.4)$ & $1.55(0.91,2.49)$ & $1.12(0.83 .1 .87)$ & 0.091 \\
\hline \multicolumn{6}{|l|}{ Knowledge of SRH issues } \\
\hline Not knowledgeable & $88(43.1)$ & $84(54.5)$ & 1 & 1 & \\
\hline Knowledgeable & 116(56.9) & $70(45.5)$ & $1.58(1.04,2.4)^{\mathrm{a}}$ & $1.46(0.84,2.53)$ & 0.184 \\
\hline
\end{tabular}

Key: 1: Reference category; AOR Adjusted odds ratio, COR Crude odds ratio

${ }^{a}$ statistically significant at $p$-value $<0.25,{ }^{\text {b }}$ statistically significant at $p$-value $<0.05$ 
Table 6 Determinants of SRH Service Utilization among rural adolescents in Guraghe Zone, Southern Ethiopia, 2020

\begin{tabular}{|c|c|c|c|c|c|}
\hline \multirow[t]{2}{*}{ Variable categories } & \multicolumn{2}{|c|}{ SRH services utilization } & \multirow[t]{2}{*}{$\operatorname{COR}(95 \% \mathrm{Cl})$} & \multirow[t]{2}{*}{ AOR(95\%Cl) } & \multirow[t]{2}{*}{$p$-value } \\
\hline & Yes (\%) & No (\%) & & & \\
\hline \multicolumn{6}{|l|}{ Age( in years) } \\
\hline $15-16$ & $85(35.5)$ & $214(43.1)$ & 1 & & \\
\hline $17-19$ & $136(61.5)$ & $282(56.9)$ & $1.21(0.88,1.68)^{\mathrm{a}}$ & & \\
\hline \multicolumn{6}{|l|}{ Sex } \\
\hline Female & $123(55.7)$ & $305(61.5)$ & 1 & 1 & \\
\hline Male & $98(44.3)$ & $191(38.5)$ & $1.27(0.92,1.75)^{\mathrm{a}}$ & $1.29(0.85,1.93)$ & 0.228 \\
\hline \multicolumn{6}{|l|}{ School enrolment status } \\
\hline No & 13(5.9) & $49(9.9)$ & 1 & 1 & \\
\hline Yes & 208(94.1) & $447(90.1)$ & $1.75(0.93,3.30)^{\mathrm{a}}$ & $1.56(0.69,3.49)$ & 0.283 \\
\hline \multicolumn{6}{|l|}{ Educational status } \\
\hline No formal education & $6(2.7)$ & $24(4.8)$ & 1 & 1 & \\
\hline Primary & $88(39.8)$ & $235(47.4)$ & $1.49(0.59,3.79)$ & $1.65(0.42,6.46)$ & 0.468 \\
\hline Secondary & $127(57.5)$ & $237(47.8)$ & $2.14(0.85,5.38)^{a}$ & $2.47(0.63,7.60)$ & 0.193 \\
\hline \multicolumn{6}{|c|}{ Current living arrangement } \\
\hline With husband/ wife & $5(2.3)$ & $29(5.8)$ & 1 & & \\
\hline With father only & $7(3.1)$ & $17(3.4)$ & $2.39(0.65,6.71)^{\mathrm{a}}$ & $2.12(0.71,4.01)$ & 0.135 \\
\hline With mother only & $17(7.7)$ & $44(8.9)$ & $2.24(0.74,5.74)^{\mathrm{a}}$ & $2.01(0.65,4.12)$ & 0.210 \\
\hline With bother parent & $192(86.9)$ & $406(81.9)$ & $2.74(1.05,6.19)^{a}$ & $2.17(0.75,5.30)$ & 0.123 \\
\hline \multicolumn{6}{|l|}{ Mother's education level } \\
\hline No Formal education & $137(64.0)$ & $261(54.5)$ & 1 & 1 & \\
\hline Primary & $36(16.8)$ & $162(33.8)$ & $0.72(0.48,1.64)$ & $0.61(0.52,1.37)$ & 0.532 \\
\hline Secondary & $28(13.1)$ & $43(8.9)$ & $1.24(0.74,2.08)$ & $1.27(0.67,2.40)$ & 0.467 \\
\hline Diploma and above & $13(6.1)$ & $13(3.0)$ & $1.91(0.86,4.22)^{\mathrm{a}}$ & $1.74(0.66,3.59)$ & 0.263 \\
\hline \multicolumn{6}{|c|}{ Father's educational level } \\
\hline No formal education & 78(38.2) & 174(38.5) & 1 & 1 & \\
\hline Primary & $72(35.3)$ & $171(37.8)$ & $0.94(0.64,1.38)$ & $1.12(0.69,1.79)$ & 0.641 \\
\hline Secondary & 33(16.2) & $87(19.3)$ & $0.85(0.52,1.37)$ & $0.82(0.46,1.44)$ & 0.490 \\
\hline Diploma and above & $21(10.3)$ & $20(4.4)$ & $2.34(1.20,4.57)^{a}$ & $1.77(0.78,4.02)$ & 0.170 \\
\hline \multicolumn{6}{|l|}{ Family size } \\
\hline$>5$ & $125(56.6)$ & $243(49.0)$ & 1 & & \\
\hline$\leq 5$ & $96(43.4)$ & $253(51.0)$ & $0.74(0.54,1.71)$ & & \\
\hline \multicolumn{6}{|c|}{ Geographical accessibility } \\
\hline $\operatorname{Far}(\geq 30 \mathrm{~min})$ & $136(61.5)$ & $398(80.2)$ & 1 & 1 & \\
\hline Close (<30 min) & $85(38.5)$ & $98(19.8)$ & $2.54(1.79,3.60)^{\mathrm{a}}$ & $2.10(1.36,3.23)^{b}$ & 0.001 \\
\hline \multicolumn{6}{|c|}{ Availability of youth clubs } \\
\hline No & $85(38.5)$ & $364(73.4)$ & 1 & 1 & \\
\hline Yes & $136(61.5)$ & 132(26.6) & $4.41(3.15,6.18)^{a}$ & $4.23(2.83,6.32)^{b}$ & $<0.001$ \\
\hline \multicolumn{6}{|l|}{ Had sexual partner/s } \\
\hline No & $170(76.9)$ & $411(82.9)$ & 1 & 1 & \\
\hline Yes & $51(23.1)$ & $85(17.1)$ & $1.45(0.98,2.14)^{\mathrm{a}}$ & $1.45(0.88,2.37)$ & 0.142 \\
\hline \multicolumn{6}{|c|}{ Had a parental discussion on SRH issues } \\
\hline No & $127(57.5)$ & $382(77.0)$ & 1 & & \\
\hline Yes & $94(42.5)$ & $114(23.0)$ & $2.48(1.77,3.48)^{a}$ & $2.09(1.37,3.20)^{b}$ & 0.025 \\
\hline \multicolumn{6}{|c|}{ Participated in peer to peer education } \\
\hline No & $71(32.1)$ & 219(44.2) & 1 & & \\
\hline Yes & $150(67.9)$ & $277(55.8)$ & $1.67(1.19,2.33)^{\mathrm{a}}$ & $1.50(0.98,2.29)$ & 0.059 \\
\hline \multicolumn{6}{|c|}{ Knowledge of SRH issues } \\
\hline Not knowledgeable & $77(34.8)$ & $318(64.1)$ & 1 & 1 & \\
\hline Knowledgeable & $144(65.2)$ & 178(35.9) & $3.34(2.39,4.66)^{\mathrm{a}}$ & $2.93(1.94,4.43)$ & $<0.001$ \\
\hline
\end{tabular}

Key: 1: Reference category; AOR Adjusted odds ratio, COR Crude odds ratio

${ }^{a}$ statistically significant at $p$-value $<0.25,{ }^{\text {b }}$ statistically significant at $p$-value $<0.05$ 
to ASRH service uptake. Based on the findings, we suggest that responsible bodies make a concerted effort to give careful credit to the ASRH needs of rural adolescents through behavioural change communication and the establishment of youth clubs.

According to the results, getting a parental discussion has a positive impact on ASRH service adoption among all adolescents, including urban and rural. Adolescents who had a parental discussion about ASRH matters were more likely to use ASRH services than those who did not. Numerous research in Africa, including Ethiopia, supplemented this [24-26, 33, 36]. This may be because, if adolescents were free to discuss ASRH topics with their parents, they would have developed more knowledge and insight about ASRH services, allowing them to practice them. To enhance adolescent-parent interaction on SRH issues, parents play a critical role. Adolescent sexual beliefs, attitudes, and behaviors were influenced by parent-adolescent sexual communication [37, 38]. According to a survey conducted in Ghana, adolescents who discuss SRH issues with their parents are more likely than other youths to delay initiation of sex and, once they do initiate sex, are more likely to use SRH services, such as contraceptive methods. Hence, rather than focusing solely on caring for the family, parents should be more nurtured by making themselves readily available to their youngsters.

Adolescents who engaged in peer education about ASRH issues had a higher likelihood of using the ASRH service. This is supported by similar studies done in Awabel district, Northern Ethiopia, Kenya, and Myanmar $[25,39,40]$. This might be because peer groups/friends are made up of people of similar ages or social groups, giving them the ability to share ideas and information about SRH problems with little to no restrictions. As a result, there would be more demand for and use of the ASRH service. Due to socio-cultural norms and taboos, economic inequality, or a lack of knowledge, adolescents in most societies find it difficult to obtain consistent and accurate information on SRH issues that affect them, such as sex, sexuality, drug use, reproductive health, HIV/AIDS, and STIs [41]. Information is almost always accessible, but it is presented in a way that is restrictive, judgmental, or unsuited to the values, views, and lifestyles of young people, and peer-to-peer education is critical in overcoming these stumbling blocks.

The current study found that adolescents who are knowledgeable about SRH issues are more likely to use ASRH services than their counterparts. Furthermore, knowledgeable rural adolescents had a higher likelihood of using SRH services. This is supported by a similar study done in northern Ethiopia [23]. This is reasonable because the more adolescents understand SRH, including its advantages, content, and service delivery points, the more likely they are to use the SRH services that are recommended. As a result, stakeholders must work together to improve adolescents' awareness of SRH resources through behavioral change communication strategies to increase ASRH service uptake.

The existence of a youth club in their immediate environment determines whether or not they use the ASRH service. Adolescents who claimed that there were youth clubs in their immediate environment were more likely to use SRH services than those who reported that there was no youth club. This is in line with research undertaken in African countries [28-30]. If youth clubs are accessible to adolescents, they may be able to increase SRH service adoption by increasing peer-to-peer dialogue, making young clients feel more relaxed and confident in seeking help [28, 42, 43]. As a result, concerned bodies' concerted efforts to expand such youth clubs in the zone, especially to rural (hard-to-reach) areas, have proven to be an effective strategy for enhancing SRH services uptake among adolescents.

The distance (perceived time spent traveling to health facilities) was found to be a significant predictor of rural adolescents' use of SRH services. Adolescents who had to travel less than $30 \mathrm{~min}$ to get to the health facility were 2.1 times more likely to use SRH services than those who had to travel more than $30 \mathrm{~min}$. This is supported by studies conducted in Mozambique and Nigeria [44, 45]. This implies that outreach programs should be expanded to reach adolescents who reside far from health facilities.

This research has both strengths and limitations. This is the first study of its kind to compare the uptake of SRH services by adolescents in urban and rural settings and may have important policy implications for the further improvement of SRH services. Furthermore, adequate samples were taken to determine the contrast between the two groups. While every effort has been taken to reduce the study's flaws, readers should proceed with caution when interpreting the results. Respondents may be prone to social desirability biases, which may have contributed to underreporting of some SRH services, since that it involves some sensitive issues and was based on self-reports. Finally, there is a likelihood of recall bias because the adolescents in this study were inquiring about events that had already occurred.

\section{Conclusions}

There was a significant difference in SRH service utilization between urban and rural adolescents. Residence, availability of youth clubs, taking part in peer education, having a parental discussion, and being knowledgeable on SRH issues were identified as significant determinants of SRH service uptake. Having parental discussion, geographical accessibility, and knowledge on SRH were 
significant predictors of SRH service uptake among rural adolescents. Since the majority of adolescents were enrolled in schools, schools should be an area of intervention to improve adolescents' knowledge of SRH services through mass media, community networks, and interpersonal/group communication. Furthermore, promoting parent-adolescent discussions, as well as peerto-peer discussions at the family and school level, should be emphasized. Stakeholders in the education and health sectors need to strengthen their efforts to establish youth clubs in places where they do not yet exist, especially in rural schools.

\section{Abbreviations}

AOR: Adjusted Odds Ratio; ASRH: Adolescent Sexual and Reproductive Health; EDHS: Ethiopian Demographic Health Survey; FMOH: Federal Ministry of Health; MLR: Multivariable Logistic Regression; ASRH: Adolescent Sexual And Reproductive Health; VCT: Voluntary HIV/AIDS Counseling, and Testing; WHO: World Health Organization.

\section{Supplementary Information}

The online version contains supplementary material available at https://doi. org/10.1186/s12889-022-12634-x.

\section{Additional file 1.}

Additional file 2.

\section{Acknowledgements}

We are grateful to the Wolkite University, College of Medicine and Health Sciences, for providing ethical clearance for this research. We are also indebted for their unrelenting support during data collection to managers at the zonal, district, and kebele levels. For their contributions to the study, our sincere gratitude also goes to our data collectors, supervisors, and study participants.

\section{Authors' contributions}

$\mathrm{AH}$ : wrote the proposal, supervised the collection of data, the entry, and analysis of data, and finally engaged in the writing and examination of the manuscript. SD: Participated in the design, methodology, data analysis, and reviewing of the manuscript critically. BB \&KL: Participated in the data review and during the study provided critical and progressive suggestions. The final paper was read and approved by all authors.

\section{Funding}

Not Applicable.

\section{Availability of data and materials}

The data used to support the findings of the current study can be obtained from the corresponding author on reasonable request via akliluhabte57@ gmail.com.

\section{Declarations}

Ethics approval and consent to participate

Ethical clearance was obtained from the Institutional Review Board(IRB) of Wolkite University, College of Medicine and Health Sciences. The IRB is made up of five members from different departments led by Mr. Samuel Dessu (samuel.desu@wku.edu.et) as a chairperson. A letter of permission was also obtained from the Guraghe Zone Health Department as well as the health offices of each of the selected districts. Following clarification about the purpose of the study, written informed consent was obtained from the participants. Informed written consent was obtained from study participants under the age of 18 using standard disclosure procedures from their parents or guardians. The confidentiality of information was secured by omitting any personal identifiers from the questionnaires. All methods were carried out in accordance with relevant guidelines and regulations. Besides, the adolescents were assured that neither the interviewer nor their parents would have access to their responses. The information was stored in a secure area where no one, except the principal investigators, had access to it.

\section{Consent for publication \\ Not applicable.}

\section{Competing interest}

We would like to assure you that, with full responsibility and communication, the document has been submitted. We indicated that there is no conflict of interest with other individuals or organizations that could influence or bias the content of the paper inappropriately.

\section{Author details}

${ }^{1}$ School of Public Health, College of Medicine and Health Sciences, Wachemo University, Hosanna, Ethiopia. ${ }^{2}$ Department of Public Health, College of Medicine and Health Sciences, Wolkite University, Wolkite, Ethiopia. ${ }^{3}$ Department of Epidemiology and Biostatistics, School of Public Health, College of Medicine and Health Sciences, Mizan Tepi University, Mizan Aman, Southern Ethiopia, Ethiopia.

Received: 12 July 2021 Accepted: 24 January 2022

Published online: 31 January 2022

\section{References}

1. WHO., Global Accelerated Action for the Health of Adolescents (AAHA!). Guidance to Support Country Implementation. 2017. Available at: http:// apps.who.int/iris/bitstream/handle/10665/255415/9789241512343-eng. pdf.jsessionid=1BC7566D91 C86EA0B3 BBE835B92DD. 2017.

2. Sawyer S, Afifi AR, Bearinger LH, Blakemore S-J, et al. Adolescence: a Foundation for Future Health. Lancet Series on Adolescent Health Lancet. 2012;379:1630-40.

3. Sheehan P, Sweeny K, Rasmussen B, Wils A, et al. Building the foundations for sustainable development: a case for global investment in the capabilities of adolescents. Lancet. 2017;390:1792-806.

4. Roudi-Fahimi F, Ashford L. Sexual and reproductive health in the Middle East and North Africa: A guide for reporters. Washington DC: Population Reference Bureau; 2008.

5. Glasier A, Gülmezoglu AM, Schmid GP, Moreno CG, Van Look PF. Sexual and reproductive health: a matter of life and death. Lancet. 2006;368(9547):1595-607.

6. UNICEF, A. 2013. Federal democratic republic of ethiopia, ministry of health,adolescent and youth reproductive health, blended learning module for the health extension programme accessed at http://www. Who.Int/reproductivehealth/publications/health_systems/9789241501 002/en/index.Html

7. WHO. Reproductive health strategy to accelerate progress towards the attainment of international development goals and targets. Geneva: World Health Organization; 2004.

8. Salam RA, Faqqah A, Sajjad N, Lassi ZS, Das JK, Kaufman M, Bhutta ZA. Improving adolescent sexual and reproductive health: A systematic review of potential interventions. J Adolesc health. 2016;59(4):S11-28.

9. Morris JL, Rushwan H. Adolescent sexual and reproductive health: The global challenges. Int J Gynecol Obstet. 2015;131:S40-2.

10. Patton G, Sawyer SM, Santelli JS, Ross DA, et al. Our Future: the Lancet Commission on Adolescent Health and Wellbeing. Lancet. 2016;387:2423-78.

11. UNICEF. 2016. Adolescent Demographics - UNICEF Data. Available at:https:// data.unicef.org/topic/adolescents/ demographics/. Accessed 24.10.2020

12. Woog V, et al. Adolescent Womens Need for and Use of Sexual and Reproductive Health Services in Developing Countries. New York: Guttmacher Institute; 2015.

13. FDRE M. National reproductive health strategy: 2006-2015. Ministry of health: Department of FH Addis Ababa. 2006. 
14. World Health Organization. WHO recommendations on adolescent sexual and reproductive health and rights. 2018.

15. WHO, UNICEF. PLANinternational, child healtyh initiatives. Adolescent Health: The Missing Population in Universal Health Coverage; 2019.

16. UN Committee on the Rights of the Child (CRC), General comment No. 20 (2016) on the implementation of the rights of the child during adolescence, 6 December2016, CRC/C/ GC/20. html. Accessed 24.9.2020. Available at: http://www.refworld.org/docid/589dad3d4

17. UNICEF U. Levels and trends in child mortality. New York: UNICEF. 2015. p. 384.

18. United Nations. 2019. Convention on the Elimination of All Forms of Discriminationagainst Women (CEDAW). 24 Oct 2019. http://www.un org/womenwatch/daw/cedaw/.Accessed.

19. McQueston K, Silverman R, Glassman A. Adolescent fertility in low-and middle-income countries: effects and solutions. Center for Global Development Working Paper. 2012;295.

20. Federation, I.P.P., Facts on the Sexual and Reproductive Health of Adolescent Women in the Developing World, April 2010. 2010.

21. Csa I. Central statistical agency (CSA) [Ethiopia] and ICF. Ethiopia and Calverton, Maryland: Ethiopia demographic and health survey, Addis Ababa; 2016.

22. Ethiopian Public Health Institute (EPHI)[Ethiopia] and ICF. Ethiopia mini demographic and health survey 2019: key indicators. Rockville: EPHI and ICF. 2019.

23. Abajobir AA, Seme A. Reproductive health knowledge and services utilization among rural adolescents in east Gojjam zone, Ethiopia: a community-based cross-sectional study. BMC Health Serv Res. 2014;14(1):138

24. Tlaye $\mathrm{KG}$, et al. Reproductive health services utilization and its associated factors among adolescents in Debre Berhan town, Central Ethiopia: a community-based cross-sectional study. Reprod Health. 2018;15(1):217.

25. Ayehu A, Kassaw T, Hailu G. Level of young people sexual and reproductive health service utilization and its associated factors among young people in Awabel District. Northwest Ethiopia PLoS One. 2016;11(3):e0151613.

26. Feleke $\mathrm{SA}$, et al. Reproductive health service utilization and associated factors among adolescents (15-19 years old) in Gondar town, Northwest Ethiopia. BMC Health Serv Res. 2013;13(1):294.

27. Gebreselassie B, et al. Assessment of Reproductive Health Service Utilization and Associated Factors Among Adolescents (15-19 Years Old) in Goba Town. Southeast Ethiopia. 2015;3(4):203-12.

28. Chirwa-Kambole E, et al. Acceptability of youth clubs focusing on comprehensive sexual and reproductive health education in rural Zambian schools: a case of Central Province. BMC Health Serv Res. 2020;20(1):42.

29. Tunusiime M, Kaduyu P, Kanakulya H, Mukisa R. Building the confidence of teachers to facilitate sexual and reproductive health information to in-school youth clubs in Uganda. Nepal J Obstet Gynecol. 2018:13(2):1-4.

30. Muula A, Lusinje AC, Phiri C, Majawa P. Youth clubs' contributions towards promotion of sexual and reproductive health Services in Machinga District, Malawi. Tanzania J Res. 2015;17(3):1-9.

31. Tegegn A, Gelaw Y. Adolescent reproductive health services in jimma city: accessibility and utilization. Ethiopian J Health Sci. 2009;19(2):91-101.

32. Gurara AM, Gizaw AB, Ayalew AK, kediro Adem A. Reproductive health service utilization and associated factors among adolescents at public school in Adama town east Shewa Ethiopia, 2018. Nursing Practice Today. 2020;7(4):275-85.

33. Melaku YA, et al. Sexual and reproductive health communication and awareness of contraceptive methods among secondary school female students, northern Ethiopia: a cross-sectional study. BMC Public Health. 2014;14:252.

34. Ansha MG, Bosho CJ, Jaleta FT. Reproductive Health services utilization and associated factors among adolescents in Anchar District, East Ethiopia. J Family Reprod Health. 2017;11(2):110.

35. The Federal Democratic Republic of Ethiopia Ministry of Health, Health Sector Transformation Plan, 2015/16 - 2019/20, October 2015. https:// www.globalfinancingfacility.org/sites/gff_new/files/Ethiopia-health-syste mtransformation-plan.pdf.

36. Hallman K. Socioeconomic disadvantage and unsafe sexual behaviors among young women and men in South Africa. 2004.

37. Wright PJ. Father-child sexual communication in the United States: A review and synthesis. J Fam Commun. 2009;9(4):233-50.
38. Organization, W.H., Helping parents in developing countries improve adolescents' health. 2007.

39. Zaw PPT, et al. Equity of access to reproductive health services among youths in resource-limited suburban communities of Mandalay City, Myanmar. BMC Health Serv Res. 2012;12(1):458.

40. Godia PM, et al. Sexual reproductive health service provision to young people in Kenya; health service providers' experiences. BMC Health Serv Res. 2013;13(1):476

41. McKeganey S, Neil P. The rise and rise of peer education approaches. Drugs: education, prevention and policy. 2000;7(3):293-310.

42. USAID, Delivering sexual and reproductive health services to young people: Key lessons from Marie StopesInternational's programmes. 2013. https://www.msichoices.org/media/2117/delivering-sexual-and-repro ductivehealth-services-to-young-people.pdf

43. Denno DM, Chandra-Mouli V, Osman M. Reaching youth with outof-facility HIV and reproductive health services: a systematic review. J Adolescent Health. 2012;51(2):106-21

44. Yao J, et al. Geographic influences on sexual and reproductive health service utilization in rural Mozambique. Appl Geogr. 2012;32(2):601-7.

45. Odo AN, et al. Sexual and reproductive health services (SRHS) for adolescents in Enugu state, Nigeria: a mixed methods approach. BMC Health Serv Res. 2018;18(1):1-12.

\section{Publisher's Note}

Springer Nature remains neutral with regard to jurisdictional claims in published maps and institutional affiliations.

Ready to submit your research? Choose BMC and benefit from

- fast, convenient online submission

- thorough peer review by experienced researchers in your field

- rapid publication on acceptance

- support for research data, including large and complex data types

- gold Open Access which fosters wider collaboration and increased citations

- maximum visibility for your research: over $100 \mathrm{M}$ website views per year

At BMC, research is always in progress.

Learn more biomedcentral.com/submissions 